\title{
Pregnancy-Related Low Back Pain Relief after Maximum Static Flexibility Program
}

\author{
Helena Andrade Figueira*, Rodrigo Gomes de Souza Vale, \\ Wilma Ferreira Guedes Rodrigues, Alan Andrade Figueira, \\ Joana Andrade Figueira, Estélio Henrique Martin Dantas
}

Laboratory of Biomedical Human Kinetics (LABIMH), Rio de Janeiro Federal University (UNIRIO), Rio de Janeiro, Brazil

Email: helenafigueira@gmail.com, rodrigovale@globo.com, wilma_fgr@msn.com, alan figueira@gmail.com, jofigueira75@gmail.com, estelio.dantas@unirio.br

Received 2 October 2014; revised 18 November 2014; accepted 4 December 2014

Copyright (C) 2014 by authors and Scientific Research Publishing Inc.

This work is licensed under the Creative Commons Attribution International License (CC BY). http://creativecommons.org/licenses/by/4.0/

\section{(c) (i) Open Access}

\begin{abstract}
Background: Pregnancy-related low back pain (LBP) impacts pregnancy. Flexibilizing facilitates movements providing posture correction and pain relief. Objective: To analyze effects of a maximum static flexibility program on pregnancy's LBP. Methods: Clinical prospective randomized controlled trial. Setting: Brazilian Governmental Health Program's prenatal care. Participants: 40 volunteer of pregnant women, gestational age between 20 and 31 weeks, with/without LBP randomly assigned to experimental group (EG) or control group (CG): EG $\mathbf{n}=20$ (E1 with LBP and E2 without LBP) and CG $n=20$ (C1 with LBP and C2 without LBP). Interventions: EG intervention was sessions of static flexion. CG received conventional medical treatment. Pain intensity was measured by visual analog scale (VAS) of pain. Chi-square, Wilcoxon and the Kruskal-Wallis statistical tests were adopted. Results: Concerning percent variation $(\Delta \%)$ E1 presented $56.4 \%$ reduction of LBP while E2, C1, C2 increased LBP by $2.9 \%, 0.1 \%, 0.5 \%$ respectively. Wilcoxon test outcome comparing pre- and post-test of experimental and control groups on pain intensity levels presented significant E1 p $<0.05$. Kruskal-Wallis test comparing post-test C1 with E1 with E2 and C2 presented $p<0.05$ (C1 post vs. E1 post: $p=0.006$; C1 post vs. E2 post: $p<0.0001$; C1 post vs. C2 post: $p=0.002$ ), showing significant effect of the experimental treatment. Conclusion: Gains on LBP for EG show that the static flexibilizing exercises reduce and prevent pregnancy-related LBP.
\end{abstract}

\section{Keywords}

Pregnancy, Flexibility, Low Back Pain, Exercise

\footnotetext{
${ }^{*}$ Corresponding author.
} 


\section{Introduction}

Pregnancy-related low back pain (LBP) has an impact on daily life for many pregnant women [1] and is characterized by pain in the lower spine responsible for physical and emotional disabilities [2]. There is an actual consensus that the lack of physical activity, sedentary lifestyle [3] and physical factors [4] as muscoskeletal and peripheral neurologic disorders [5] are mainly responsible for that, although the etiology is multifactorial and poorly understood [1], giving the complex interplay of muscles, bones, and soft tissue that comprise the area [6].

The acute effects of stretching on flexibility — which increases the motor cortical inhibition [7] — training can either be viscoelastic [8] or neural [9]. Maximal flexibility training (flexibilizing) is commonly used to increase the pain-free range of motion about a joint in an attempt to promote better performances and/or as a technique for injury prevention in the clinical setting [10]. Although stretching may reduce the acute incidence of muscle strain injuries, acute muscle stretch may moderately impair muscle performance if the total duration of stretch is above 60 seconds [11]. Flexibilizing improves the ability of muscle contraction plus the nerve reflex timing as well as blood supplies, stretching knees, facilitating walking as well as many other daily regular movements [12]. For LBP [13] in pregnancy [14], physical activity provides posture correction, relief of pain and great ability for daily living activities [15]. In Brazil, a Health Governmental Program was implemented by the Federal Government [16], arising as a public policy focused on the low-income population providing essential guidelines and attention on promoting healthy living, prevention, rehabilitation, and support [17]. This study aimed to analyze effects of a training program of static flexibility, using maximum intensity (flexibilizing) on low back pain, in pregnant women served by a Health Governmental Program.

\section{Sample and Methods}

The sample was composed by 40 pregnant women randomly assigned from the 102 pregnant women gestational age (GA) between 20 and 31 weeks served by the Cuitegi municipality, in Paraiba, Brazil, Governmental Health Program prenatal care to either an experimental group (EG) $n=20$ or a control group (CG) $n=20$. The EG received an intervention with sessions of static flexibilizing and the CG did not undergo any intervention, instead receiving conventional prenatal treatment. Pain intensity was measured by visual analog scale (VAS) of pain that ranges from: $0=$ no pain; 1 - $3=$ low intensity pain; 4 - $6=$ moderate intensity pain; 7 - $8=$ intense pain; 9 $10=$ unbearable pain.

The inclusion criteria were being over 18 years old, in gestational age between 20 and 31 weeks, and enrolled in the studied Health Governmental Program prenatal care. From those included we had as exclusion criteria: high-risk pregnancy, and/or be engaged in any physical therapy for LBP, and/or presenting any medical contraindication.

Randomization occurred by simple random sampling. Initially the 102 pregnant women-in gestational age between 20 and 31 weeks - received a questionnaire on personal data, daily routine, physical activity, and LBPreported via VAS pain. After that, we asked them to get into two lines-with LBP (different of 0 ) or without LBP $(=0)$ - to return the filled questionnaires. The first ten pregnant women with no LBP returning the filled questionnaires were randomly drawn to the control group (CG), and the next ten to the experimental group (EG). As we had only twenty pregnant women with no LBP, after accepting the twenty first in their line, we dismissed the ones with LBP in order to keep the groups even. Therefore four groups were formed: EG subdivided in E1 (n $=10)$ with LBP and E2 $(n=10)$ without LBP and CG subdivided in C1 $(n=10)$ with LBP and C2 $(n=10)$ without LBP.

Body mass $(\mathrm{kg})$ and height $(\mathrm{cm})$ of the pregnant women were measured before the intervention, using a scale with stadiometer calibrated by Brazilian National Institute of Metrology, respecting the requirements of International Standards for Anthropometric Assessment [18]. The individual body mass index (BMI) was calculated, with these body mass and height data.

At the EG intervention a physical educator supervised all activities. The intervention involved 18 sessions of static flexibilizing of 45 minutes each, twice a week. The training of static flexibilizing was performed as follows: at first, warm-up for 10 minutes, to initiate the activity (formally the first part of any physical activity, preparing both physiologically and psychologically), dancing smooth and happy music.

After warming up, the second part was the flexibilizing, lasting 25 minutes. During this part, each exercise was repeated 10 times, with a permanence time of 10 seconds (controlled by a digital stopwatch) in the posture. The exercises were resumed in remaining in two static positions: 1 ) the lying posture in supine position with the 
upper limbs abducted about $30^{\circ}$ and the forearms supine, hips flexed, abducted, and laterally rotated, with foot soles touching each other; 2) the lying posture with hip flexion, knee extension, and dorsiflexion of the ankle [19].

After this second part composed by the flexibilizing exercises, the final part was relaxing. This was lasting for 10 minutes.

To control the activity intensity, the participants were instructed to identify the level of perceived exertion, using a Scale of Perceived Exertion in flexibility-PERFLEX [20], keeping it within the limit of 65 to 75 . The experimental group reported an average of perceived exertion of $72 \pm 6$.

This research did not interfere with the medical routine for the CG therefore it followed the standard procedure according to medicine guidelines. Participants in the CG received routine medical advice with medication prescription if needed with postural guidelines for LBP prevention and/or relief in the clinical prenatal care of the studied Governmental Health Unit. The CG was monitored by records of medical consultations, scheduled regularly for every two weeks.

For data treatment it was adopted the statistical software SPSS, version 17.0. The descriptive statistics estimated mean and standard deviation of the dependent variables age, weight, height, body mass index, and gestational age. The distribution of frequency of pain intensity measured by VAS Pain before and after intervention was compared with the Chi-square test. The pain level of VAS scale was analyzed by Wilcoxon test and the Kruskal-Wallis test, followed by Dunn's test was used to identify the possible differences intergroup after intervention. The study adopted the level of $\mathrm{p}<0.05$ for statistical significance.

This research is a clinical prospective randomized controlled trial following strictly the Helsinki Convention [21]. All the participants signed the Free Consented Participation Term [22] and the research's project was previously approved by the Research Ethics Committee of Santa Emilia de RODAT University, in João Pessoa municipality, Paraíba, Brazil, under the protocol number 1022.0.000.125-09.

\section{Results}

The descriptive characteristics of the sample group present homogeneity in age, weight, height, body mass index (BMI), gestational age (GA), as shown in Table 1.

Conventional treatment for low back pain adopted for the control group is described in Table 2. The control groups C1 and C2 $(n=20)$ attended the service for a conventional treatment's guidance for low back pain, where the adopted measures (Table 2) were: routine medical advice with medication prescription, resting orientation, counseling and postural guidelines for the treatment of LBP in the clinical prenatal care of the studied Governmental Health Unit.

Distribution of frequency of pain's intensity for groups with LBP is presented in Table 3. The pain intensity for LBP $(n=20)$ groups, either experimental (E1) or control (C1) measured using visual analog scale of pain (VAS Pain) presented in Table 3, showed that the proportion of zero score found at the beginning of the program progressively increased, reaching the percentage of $60 \%$ without LBP at the end of the experiment. The initial VAS Pain grades 9 - 10 reported by 40\% of the E1 and C1 pregnant women-by the beginning of this research reduced to $10 \%$ at its end. Therefore, the pre- and post-test outcome compared with the Chi-square test was significant for the experimental group $(p<0.05)$, what did not occur with the control group $(p=0.34)$. Intensity frequency of LBP in both groups (Table 3) — absolute and percent—showed that E1 presented a significant result concerning reduction and prevention of LBP compared to C1.

Table 4 presents the analysis of pain intensity level in pre-and post-test of experimental and control groups with Wilcoxon test of E1 pretest compared with posttest presenting $\mathrm{p}<0.05$ (E1 pre vs. E1 post: $\mathrm{p}=0.040$ ). The Kruskal-Wallis test comparing post-test C1 with E1 with E2 and C2 resulting p < 0.05 (C1 post vs. E1 post: p = 0.006; C1 post vs. E2 post: $\mathrm{p}<0.0001$; C1 post vs. C2 post: $\mathrm{p}=0.002)$. Concerning percent variation $(\Delta \%) \mathrm{E} 1$ presented a LBP reduction of $56.4 \%$ whereas the other groups (E2, C1, C2) increased respectively $2.9 \%, 0.1 \%$ and $0.5 \%$. Therefore, the experimental treatment had significant effect: the pain factor presented significant values in the range of LBP perception. After the intervention, pregnant women in E1 (with LBP) reported a decrease in average LBP intensity level in post-test, compared with pregnant women in C1 (with LBP). Analyzing LBP intensity in pre- and post-test of experimental and control groups-compared with the Kruskal-Wallis test followed by Dunn's test to identify the possible intergroup groups differences-C1 vs. E2 and vs. C2, which informed no LBP - grade zero (no pain) in the VAS: unchanged for EG at the beginning of the sessions and at the 
Table 1. Sample’s descriptive characteristics distribution.

\begin{tabular}{ccc}
\hline & EG $(\mathrm{n}=20)$ & CG $(\mathrm{n}=20)$ \\
\cline { 2 - 3 } & Mean \pm SD & Mean \pm SD \\
\hline Age (years) & $24.90 \pm 3.87$ & $25.90 \pm 4.54$ \\
Weight $(\mathrm{cm})$ & $153.05 \pm 3.86$ & $150.41 \pm 4.23$ \\
Height $(\mathrm{kg})$ & $52.10 \pm 1.90$ & $51.19 \pm 1.82$ \\
BMI $\left(\mathrm{kg} / \mathrm{m}^{2}\right)$ & $22.72 \pm 1.46$ & $23.09 \pm 1.53$ \\
GA (week) & $23.90 \pm 3.75$ & $23.35 \pm 3.70$ \\
\hline
\end{tabular}

EG = Experimental Group; CG = Control Group; $\mathrm{SD}$ = Standard Deviation; BMI = Body Mass Index; GA = Gestational Age.

Table 2. Description of the conventional treatment's guidance for low back pain (LBP) adopted for the control groups C1 and C2 $(n=20)$.

\begin{tabular}{ccc}
\hline & $\mathrm{n}$ & $\%$ \\
\hline No Guidance at All & 3 & $15 \%$ \\
Rest & 4 & $20 \%$ \\
Medication & 5 & $25 \%$ \\
Postural Guidance & 3 & $15 \%$ \\
Avoiding Heavy Lifting & 3 & $15 \%$ \\
Medical Certificate & 2 & $10 \%$ \\
\hline
\end{tabular}

Table 3. Distribution of frequency of pain's intensity via visual analog scale of pain (VAS Pain) for groups with LBP $(\mathrm{n}=20)$, both experimental (E1) and control (C1).

\begin{tabular}{ccccc}
\hline \multirow{2}{*}{ VAS Pain Scale } & \multicolumn{3}{c}{ Pre } & \multicolumn{2}{c}{ Post } \\
\cline { 2 - 5 }$(0)$ & E1 (n) & C1 (n) & E1 (n) & C1 (n) \\
\hline$(1-3)$ & $00(00 \%)$ & $0(00 \%)$ & $06(60 \%)$ & $0(00 \%)$ \\
$(4-5)$ & $01(10 \%)$ & $2(20 \%)$ & $01(10 \%)$ & $2(20 \%)$ \\
$(6-8)$ & $03(30 \%)$ & $3(30 \%)$ & $01(10 \%)$ & $3(30 \%)$ \\
$(9-10)$ & $02(20 \%)$ & $3(30 \%)$ & $01(10 \%)$ & $2(20 \%)$ \\
Total & $04(40 \%)$ & $2(20 \%)$ & $01(10 \%)$ & $3(30 \%)$ \\
\hline
\end{tabular}

VAS Pain Scale = Visual Analog Scale of Pain; E1 = Experimental Group with LBP; C1 = Control Group with LBP; Pre = Pre-test; Post = Post-test; $\mathrm{n}=$ Absolute frequency of individual (percent: \%); Chi-square test: E1 group pre vs. post: $\mathrm{p}=0.001^{*}$; C1 group pre vs. post: $\mathrm{p}=0.34$.

Table 4. Analysis of pain intensity level by VAS scale in pre- and post-test of experimental and control groups after intervention period.

\begin{tabular}{ccccc}
\hline Situation & Group & Mean \pm SD (Pre-test) & Mean \pm SD (Post-test) & $\Delta \%$ \\
\hline \multirow{2}{*}{ With Pain } & E1 (EG: $=10)$ & $3.9 \pm 1.10$ & $1.7 \pm 1.00^{*}$ & -56.4 \\
& C1 (CG:n $=10)$ & $3.5 \pm 1.10$ & $3.6 \pm 1.10^{* *}$ & 2.9 \\
\multirow{2}{*}{ Without Pain } & E2 (EG:n $=10)$ & $1.0 \pm 0.00$ & $1.1 \pm 0.01$ & 0.1 \\
& C2 (CG: $=10)$ & $1.0 \pm 0.00$ & $1.5 \pm 0.85$ & 0.5 \\
\hline
\end{tabular}

EG = Experimental Group; CG = Control Group; E1 = Experimental Group with LBP; C1 = Control Group with LBP; E2 = Experimental Group without LBP; C2 = Control Group without LBP; SD = Standard Deviation; ${ }^{*} \mathrm{p}<$ 0.05 , E1 pre vs. post, by Wilcoxon test; ${ }^{* *} \mathrm{p}<0.05$, C1 post vs. E1 post, vs. E2 post, vs. C2 post, by Kruskal-Wallis test.

end; increasing 20\% the complaining of LBP in CG, mostly of moderate intensity (4 - 6). Analyzing the results of E2 and C2 groups, respectively experimental and control (no LBP), it can be observed that both after the ex- 
periment remained unchanged.

\section{Discussion}

The present study found that pregnant women served in a prenatal care of a Brazilian Governmental Health Program and reporting LBP, benefited from participating in a program of static flexibilizing. These data are consistent with studies showing that physical activity prevents and treats pregnancy-related LBP [2] [3] [13] [23], as instructed by both American College of Sports Medicine [15] and American College of Obstetrician and Gynecologists-ACOG [24].

Comparing the groups with LBP it is observed that the perceived LBP decreased significantly in the EG compared with the CG. In E2 and C2 groups (no LBP) it was verified that the intervention was suggestive of prevention for the non appearance of LBP in the majority (80\%) of E2 that was not observed in C2. It was verified that conventional treatment for pregnancy-related LBP, performed in health facilities by professionals during the consultations of prenatal care, to which CG was submitted, based on drugs and guidance had no effect for relief or prevention of LBP-presenting no significant result-as there was no reduction of LBP in CG (group not subject to static exercises). Promoting good posture and regular exercise can be recommended as a method to relieve LBP in pregnant women [25], plus, joint flexibility maintenance sums-up, easing the movement [26].

For the experimental group, guidelines were individually given on anatomical and ergonomics; that is proved to decrease LBP [27], therefore, the recommended treatment must include adequate information and reassurance of the patient, as well as flexibilizing exercises [13].

Physical activity in pregnancy-related LBP providing posture correction, relief of pain and greater ability in performing daily living activities was confirmed in this research where pregnant women from the experimental group reported that exercises were boosting their: posture, self-esteem, ability to perform daily living activities, as much as having a better understanding of pregnancy and its bodily changes.

The question of LBP in pregnancy stimulated many studies in different areas as LBP is more prevalent in pregnant women —with a reported prevalence of 57\% to 69\% [28] - than in the general population [29]. Much has already been done to minimize its problems, but despite healthcare providers' beliefs about exercise during pregnancy being positive, not everyone is aware of or following current ACOG recommendations [30]. Therefore it is important to look again at something that establishes an ideal behavior, standardized and recommended by experts, which can be used by all professionals, as is easily accessible and understandable.

\section{Conclusion}

With the flexibility program experimental treatment, it was observed that the characteristics of LBP in pregnancy, regarding frequency, intensity and presence of pain suffered changes informed in post-test analysis of pain. The pregnant women of experimental group showed significant improvement and prevention of pain in post-test, compared with those of control group. The static exercises contributed to reduction or prevention of LBP in pregnant women attended by this Family Health Program. The conventional treatment, based on drug therapy and resting, did not present significant result for LBP in pregnancy.

\section{Suggestion}

We highlight this study's importance since this is one of few randomized controlled clinical trials evaluating a static flexibility program for LBP in pregnant women enrolled in governmental health programs. Despite its homogeneity of sample in age, gestational age and BMI, we suggest for future studies to increase sample's size.

\section{References}

[1] Katonis, P., Kampouroglou, A. and Alpantaki, K. (2011) Pregnancy-Related Low Back Pain. Hippokratia, 15, 205210.

[2] Pennick, V.E. and Young, G. (2007) Interventions for Preventing and Treating Pelvic and Back Pain in Pregnancy. Cochrane Database of Systematic Reviews, 18, CD001139.

[3] Granath, A.B., Hellgren, M.S. and Gunnarsson, R.K. (2006) Water Aerobics Reduces Sick Leave Due to Low Back Pain during Pregnancy. Journal of Obstetric, Gynecologic, Neonatal Nursing, 35, 465-471. 
http://dx.doi.org/10.1111/j.1552-6909.2006.00066.x

[4] Wu, W., Meijer, O., Bruijn, S., Hu, H., van Dieën, J., Lamoth, C., et al. (2008) Gait in Pregnancy-Related Pelvic Girdle Pain: Amplitudes, Timing, and Coordination of Horizontal Trunk Rotations. European Spine Journal, 17, 11601169. http://dx.doi.org/10.1007/s00586-008-0703-0

[5] Borg-Stein, J., Dugan, S.A. and Gruber, J. (2005) Musculoskeletal Aspects of Pregnancy. American Journal of Physical Medicine \& Rehabilitation, 84, 180-192. http://dx.doi.org/10.1097/01.PHM.0000156970.96219.48

[6] Alappattu, M.J. and Bishop, M.D. (2011) Psychological Factors in Chronic Pelvic Pain in Women: Relevance and Application of the Fear-Avoidance Model of Pain. Physical Therapy, 91, 1542-1550. http://dx.doi.org/10.2522/ptj.20100368

[7] Oliveri, M., Caltagirone, C., Loriga, R., Pompa, M.N., Versace, V. and Souchard, P. (2012) Fast Increase of Motor Cortical Inhibition Following Postural Changes in Healthy Subjects. Neuroscience Letters, 530, 7-11. http://dx.doi.org/10.1016/j.neulet.2012.09.031

[8] Yamaguchi, T. and Ishii, K. (2005) Effects of Static Stretching for 30 Seconds and Dynamic Stretching on Leg Extension Power. The Journal of Strength and Conditioning Research, 19, 677-83.

[9] McHugh, M.P. and Cosgrave, C.H. (2010) To Stretch or Not to Stretch: The Role of Stretching in Injury Prevention and Performance. Scandinavian Journal of Medicine \& Science in Sports, 20, 169-181.

[10] Marek, S.M., Cramer, J.T., Fincher, A.L., Massey, L.L., Dangelmaier, S.M., Purkayastha, S., et al. (2005) Acute Effects of Static and Proprioceptive Neuromuscular Facilitation Stretching on Muscle Strength and Power Output. Journal of Athletic Training, 40, 94.

[11] Kay, A.D. and Blazevich, A.J. (2012) Effect of Acute Static Stretch on Maximal Muscle Performance: A Systematic Review. Medicine \& Science in Sports \& Exercise, 44, 154-64. http://dx.doi.org/10.1249/MSS.0b013e318225cb27

[12] Dantas, E.H.M., Daoud, R., Trott, A., Nodari, R.J. and Conceicao, M.C.S.C. (2011) Flexibility: Components, Proprioceptive Mechanisms and Methods. Biomedical Human Kinetics, 3, 39-43.

[13] Vleeming, A., Albert, H., Östgaard, H., Sturesson, B. and Stuge, B. (2008) European Guidelines for the Diagnosis and Treatment of Pelvic Girdle Pain. European Spine Journal, 17, 794-819. http://dx.doi.org/10.1007/s00586-008-0602-4

[14] Stutzman, S.S., Brown, C.A., Sylvia, M.J., Godwin, M., Smith, G.N., Parlow, J.L. and Kisilievsky, B.S. (2010) The Effects of Exercise Conditioning in Normal and Overweight Pregnant Women on Blood Pressure and Heart Rate Variability. Biological Research for Nursing, 12, 137-148. http://dx.doi.org/10.1177/1099800410375979

[15] ACSM (2006) Impact of Physical Activity during Pregnancy and Postpartum on Chronic Disease Risk. Medicine \& Science in Sports \& Exercise, 38, 989-1006.

[16] Figueira, H., Figueira, J., Mello, D. and Dantas, E. (2008) Quality of Life throughout Ageing. Acta Medica Lituanica, 15, 169-172.

[17] Figueira, H.A., Figueira, A.A., Cader, S.A., Guimarães, A.C., Oliveira, R.J., Figueira, J.A., et al. (2012) Effects of a Physical Activity Governmental Health Programme on the Quality of Life of Elderly People. Scandinavian Journal of Public Health, 40, 418-422. http://dx.doi.org/10.1177/1403494812453885

[18] Marfell-Jones, M., Olds, T., Stewart, A. and Carter, L. (2006) International Standards for Anthropometric Assessment. The International Society for the Advancement of Kim Anthropometric (ISAK), Potchefsroom, South Africa.

[19] Bonetti, F., Curti, S., Mattioli, S., Mugnai, R., Vanti, C., Violante, F.S., et al. (2010) Effectiveness of a "Global Postural Reeducation” Program for Persistent Low Back Pain: A Non-Randomized Controlled Trial. BMC Musculoskeletal Disorders, 11, 285. http://dx.doi.org/10.1186/1471-2474-11-285

[20] Dantas, E.H.M., Salomão, P.T., Vale, R.G.S., Achour-Júnior, A., Simão, R. and Figueiredo, N.M.A. (2008) Scale of Perceived Exertion in the Flexibility (PERFLEX): A Dimensionless Tool to Evaluate the Intensity? Fitness \& Performance Journal, 7, 289-294.

[21] Declaration of Helsinki (2008) Ethical Principles for Medical Research Involving Human Subjects. Adopted by the 18th WMA in Helsinki in 1964 and Revised by the WMA: Last Revision in Seoul.

[22] Goodyear, M., Krleza-Jeric, K. and Lemmens, T. (2007) The Declaration of Helsinki. British Medical Journal, 335, 624.

[23] Noren, L.S.O. and Johansson, G.H.C.O. (2002) Lumbar Back and Posterior Pelvic Pain during Pregnancy: A 3-Year Follow-Up. European Spine Journal, 11, 267-271. http://dx.doi.org/10.1007/s00586-001-0357-7

[24] ACOG, American College of Obstetrician and Gynecologists (2002) Committee Opinion \#267: Exercise during Pregnancy and the Postpartum Period. Obstetrics \& Gynecology, 99, 171-173. http://dx.doi.org/10.1016/S0029-7844(01)01749-5

[25] Shim, M.J., Lee, Y.S., Oh, H.E. and Kim, J.S. (2007) Effects of a Back-Pain-Reducing Program during Pregnancy for Korean Women: A Non-Equivalent Control-Group Pretest-Posttest Study. International Journal of Nursing Studies, 44, 19-28. http://dx.doi.org/10.1016/j.ijnurstu.2005.11.016 
[26] Kato, E., Oda, T., Chino, K., Kurihara, T., Nagayoshi, T., Fukunaga, T., et al. (2005) Musculotendinous Factors Influencing Difference in Ankle Joint Flexibility between Women and Men. International Journal of Sport and Health Science, 3, 218-225.

[27] Gutke, A., Ostgaard, H.C. and Oberg, B. (2008) Association between Muscle Function and Low Back Pain in Relation to Pregnancy. Journal of Rehabilitation Medicine, 40, 304-311. http://dx.doi.org/10.2340/16501977-0170

[28] Lisi, A.J. (2006) Chiropratic Spinal Manipulation for Low Back Pain of Pregnancy: A Retrospective Case Series. Journal of Midwifery \& Women's Health, 51, e7-e10. http://dx.doi.org/10.1016/j.jmwh.2005.09.001

[29] Gutke, A., Ostgaard, H.C. and Oberg, B. (2008) Predicting Persistent Pregnancy-Related Low Back Pain. Spine, 33, E386-E393. http://dx.doi.org/10.1097/BRS.0b013e31817331a4

[30] Bauer, P.W., Broman, C.L. and Pivarnik, J.M. (2009) Exercise and Pregnancy Knowledge among Healthcare Providers. Journal of Women's Health, 19, 335-341. http://dx.doi.org/10.1089/jwh.2008.1295 
Scientific Research Publishing (SCIRP) is one of the largest Open Access journal publishers. It is currently publishing more than 200 open access, online, peer-reviewed journals covering a wide range of academic disciplines. SCIRP serves the worldwide academic communities and contributes to the progress and application of science with its publication.

Other selected journals from SCIRP are listed as below. Submit your manuscript to us via either submit@scirp.org or Online Submission Portal.
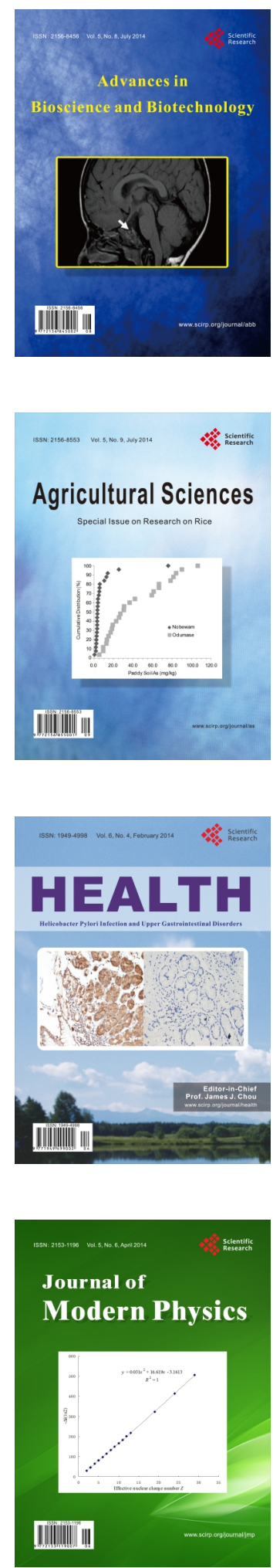
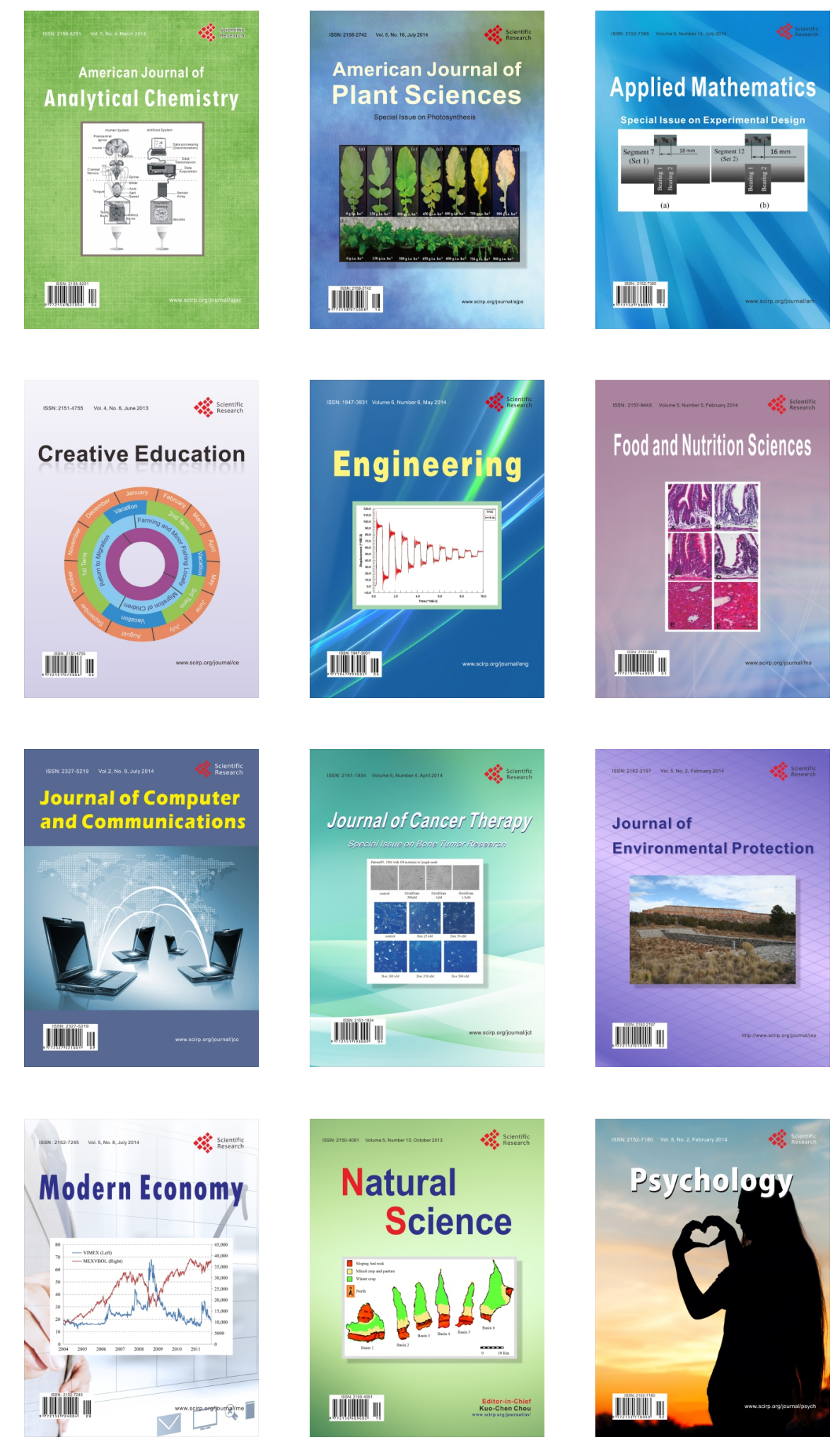